\title{
NOTES ON THE PRODUCTION OF STREAM BRYOPHYTES IN THE HIGH PYRENEES (FRANCE)
}

\author{
by F. H. Dawson ${ }^{1}$.
}

\begin{abstract}
SUMMaRY.
The production estimate for Fontinalis squamosa of $92 \mathrm{gm} \mathrm{m}^{-2}$ was a minimum one assuming an annual branching pattern. Standing crops for the total stream area of bryophytes of $325 \mathrm{gm} \mathrm{m}^{-2}$ for the site at Artigusse and of $92 \mathrm{gm} \mathrm{m} \mathrm{m}^{2}$ for the Estaragne tributary were recorded. The area covered was however high in the former and very low in the latter (only $7 \%$ ). The maximum recorded standing crops were $1960 \mathrm{gm} \mathrm{m}^{-2}$ for Cratoneuron commutatum and $682 \mathrm{gm} \mathrm{m}^{-2}$ for Fontinalis and Fissidens combined.

The splash zone around a small water chute is described.
\end{abstract}

\section{Notes sur la production de bryophytes dans des torrents pyrénéens.}

Une production minimale de $92 \mathrm{~g} / \mathrm{m}^{2}$ a été estimée pour Fontinalis squamosa en supposant une ramification annuelle. Les biomasses de bryophytes ont été évaluées à $325 \mathrm{~g} / \mathrm{m}^{2}$ au ruisseau d'Artigusse et à $92 \mathrm{~g} / \mathrm{m}^{2}$ à un affluent du ruisseau d'Estaragne. L'aire recouverte était cependant élevée pour la première station et faible pour la seconde ( $7 \%$ seulement). Les biomasses maximales ont été évaluées à $1960 \mathrm{~g} / \mathrm{m}^{2}$ pour Cratoneuron commutatum et à $682 \mathrm{~g} / \mathrm{m}^{2}$ pour Fontinalis et Fissidens réunies.

Enfin est décrite la zonation des mousses autour d'une petite cascade.

Aquatic bryophytes form a potential food source for aquatic consumers, the importance of which is unestablished, but in addition they shelter algae in considerable quantities (Décamps and Lafont 1974). In highland streams which are subjected to frequent and violent flushing loose organic material is washed in from the banks and together with algae is often carried far downstream before settling out. In such situations bryophytes act as a stable or basal level of available food. It is also necessary to emphasise their importance in highland streams as shelter for animals, particularly the larvae of brachycentrid caddis of the genus Micrasema in the streams studied.

Hynes (1970) and Arnold and Macan (1969) have surveyed the importance of bryophytes in aquatic communities. Other studies

1. The Freshwater Biological Association, River Laboratory, East Stoke, Wareham, Dorset. 
of aquatic bryophytes have usually been descriptive (Glime 1968) or part of an invertebrate or community study (Minshall and Kuehne 1969).

\section{THE STUDY SITES}

The work was carried out at sites in the Couplan and Oredon basin of the Néouvielle Massif of the Hautes Pyrenees, France.

The climate and sites are described in detail by Décamps (1967).

The first site, a stream at Artigusse, $42^{\circ} 49^{\prime} \mathrm{N} .0^{\circ} 12^{\prime} \mathrm{E}$. was a small soft water spring arising from aquifers in schist at an altitude of $1600 \mathrm{~m}$. The gradient of the stream was about 1/15; the flow was constant throughout the year. The bed was of irregular schist boulders of 0.1-1 $\mathrm{m}$ diameter which had been dislodged from the adjacent south facing slope by snow. The stream was not covered by ice in winter because the minimum water temperature was $4{ }^{\circ} \mathrm{C}$; the annual range was $4-8^{\circ} \mathrm{C}$.

The second site, Artigusse water chute, was immediately downstream of the first, being $30 \mathrm{~m}$ from the source at which point the water fell two metres vertically over a large block on to bryophyte covered rocks, producing a splash area with a distinct and regular zonation of bryophytes.

The third site, a tributary of Estaragne Stream, $42^{\circ} 49^{\prime}$ N. $0^{\circ} 9^{\prime}$ E. at $2000 \mathrm{~m}$, had a gradient of $1 / 1$ and was littered with large and small schist boulders. Above water level, the larger boulders were covered with saxifrages, the less stable smaller ones were often completely bare. In the late spring the stream was fed by snow melt, but the flow was very much reduced by the autumn. In summer the temperature of the water increased rapidly with increasing distance from the source. Only the permanent stream area was studied. The slope faced North-west and was snow covered until May. The stable areas were dominated by Cratoneuron commutatum (Hedw.) Roth and Brachythecium rivulare (Bruch) B. and S.

\section{THE METHODS}

The standing crop was determined at each site by taking samples of bryophytes periodically. The moss was removed from the stones, sorted and sealed in polythene bags. Unattached bryophytes, caught again on stones, were also collected but treated separately. Samples were washed and the material retained by a $1 \mathrm{~mm}$ sieve was dried at $105{ }^{\circ} \mathrm{C}$ for 24 hours. The dried samples were sealed in polythene bags, allowed to cool and weighed. Small sub-samples were ashed at $525{ }^{\circ} \mathrm{C}$ overnight. 
After removing the bryophytes from the stones by hand, several of the smaller ones from the transects at Artigusse were subsequently cleaned by means of a scalpel blade resulting in the removal of only another $7 \mathrm{gm} \mathrm{m}^{-2}$ mean weight of firmly attached stem. The correction factor was applied to the results. Material from section 4 at Artigusse was re-washed a further three times to remove any further debris, recovering all recognisable bryophyte fragments from the washings. A reduction of only five per cent after three washings was noted. The normal method was therefore one washing to remove the debris, because further washings removed more bryophyte fragments than debris.

The standing crops per unit area of the plan! community were used to determine the maximum standing crop, which after correction for losses such as leaf damage and leaf fall during the season provide an estimate of the annual production (Vollenweider 1969). However for a community of perennial plants the age structure must be established before the annual production can be estimated.

\section{Site One. Artigusse stream.}

Twenty metres of stream which were fairly uniform were selected for sampling by two methods :

1) Because of the irregular nature of the stream bed, stones were selected at random in preference to small quadrats. The area of the upper surface was determined by measuring the length and mean width of the stone in the same orientation as in the stream, thus giving the potential area of attachment. The mean depth of water above each stone sampled was measured.

2) The second method of estimating standing crop was by removal of bryophytes from four $0.5 \mathrm{~m}$ wide belt transects. The stream was divided at right angles to the flow into four strata each of about five metres and the transects were taken from their downstream edges. The width of the stream at the upper and lower margins of each transect was measured. Subsequent samples were to be taken upstream of the previous season's but regrowth was very slow and none were taken.

\section{Site Two. Artigusse water chute.}

The quantity of water falling per unit area in the area of bryophyte zonations was estimated using plastic containers of $8.8 \mathrm{~cm}$ diameter placed along transects radiating outwards from the centre of the water chute. The containers were covered and located in the moss, level with the surface, uncovered for a timed 
interval and recovered. The containers were only allowed to fill halfway to minimise splash out. The volume of water was measured. The results from twenty stations were used to construct a map of isohyets, that is, a map with lines joining places of equal splash.

A steel needle was used to measure the depths of moss and $5 \mathrm{~cm}$ cores were taken at regular intervals across the transects.

The distribution of bryophyte species was mapped and related to the distribution of water splash.

\section{Site Three. Estaragne Tributary.}

Three distinct surfaces could be recognised :

1) surfaces and faces of rocks in contact with rapidly flowing water.

2) surfaces of rocks in contact with slowly flowing water, mainly near the margins of the stream, and

3 ) regions on and between small rocks and those in shaded positions. Small samples were taken at random from the three groups of bryophyte covered areas using a $3.4 \mathrm{~cm}$ circular corer. A map was constructed as a basis for estimating the standing crop from measurements of the total area and biomass for unit area of each type of surface. The areas covered by each type of surface were calculated from the map using a planimeter. The total standing crop was calculated for the area of each type and summed. The standing crop was expressed per unit area of actual inclined surface and was not corrected for the vertical projection. This is not directly comparable with other sites.

\section{RESULTS AND DISCUSSION}

\section{The Plants.}

At Artigusse, Fontinalis squamosa Hedw., is the dominant aquatic plant. Growth is apical and the main axis lengthens with time in the direction of water flow. It is unlike a land bryophyte such as Sphagnum (Clymo 1970), because only stems accumulate, not both stems and leaves; leaves are mainly lost by insect damage and abrasion within a year of their development as there is no abscission layer. The bases of leaves may however persist much longer as very small stumps. The older stems do not produce any new growth and serve solely as the connection between the substratum and the leafy stem. Growth rates are limited by the diffusion of free carbon dioxide to the plant through water 
(Gessner 1959). This characteristic, probably accounts for the distribution of Fontinalis species which are found in turbulent water, in springs and in highly organic lakes. $F$. squamosa is typical of soft waters (Nicolau-Guillaumet 1959, Frost 1942, Watson 1959).

The age of Fontinalis plants was determined by observing the frequency of the series of branching, assuming that a new series of branches is started each year and that process is continuous. The majority of plants were between three and five years old but one plant may have been nine years old. Both very small and very large plants were difficult to age but were not excluded.

Fissidens polyphyllus Wils. was abundant at Artigusse growing particularly in deep fissures the presence of which is not properly reflected in the mean depth results. (Table 2). No regular growth patterns at all were observed. Very little damage or leaf loss was apparent. The available light seemed insufficient to produce the recorded standing crop in a single season.

Cratoneuron commutatum (Hedw.) Roth. 'was present in the splash zone of the Artigusse waterchute and on the Estaragne tributary.

C. commutatum Forma falcatum (Brid.) Moenk. was typical of the higher velocities of the water chute, it was exceedingly robust with thick erect stems (Nyholm 1954, p. 420). Forma fluctans Wijh. et Marg. was present in the outer zones of the water chute and in the Estaragne tributary. It was a soft, non-erect mat with apex tips slightly raised above the general mat.

Hepatics were uncommon in transects and preferred shady conditions, amongst the bases of $F$. squamosa and on the sides of boulders in slack water.

\section{The Standing Crops.}

\section{Artigusse Stream.}

Random quadrats, or transects of comparable area, removed a lot of material and were too destructive to the system. An attempt was made to reduce the quantity removed, by sampling the crop per unit area of attachment thus avoiding the damage loss caused by cutting across the plants at different levels. This method also resulted in a high variance for the standing crop estimate, probably due to the differing ages of plants on the stones (Tables 1 and 2). Belt transects probably contained a representative age sample of plants.

The transects show an optimum depth for $F$. squamosa of 30 $40 \mathrm{~cm}$ of water. The standing crop determined per unit area of attachment showed no significant variation with depth. (Table 1). 
TABLE 1. - Standing crop of bryophytes by attachment area, Artigusse Stream.

\begin{tabular}{crc}
\hline Area $\mathrm{m}^{2}$ & $\mathrm{dry}$ wt $\mathrm{gm} \mathrm{m}^{-2}$ & Depth $\mathrm{m}$ \\
\hline 0.029 & 24 & 25 \\
0.112 & 220 & 25 \\
0.072 & 264 & 30 \\
0.014 & 191 & 30 \\
0.051 & 183 & 15 \\
0.063 & 238 & 15 \\
0.011 & 9 & 40 \\
0.036 & 17 & 40 \\
0.054 & 93 & 40 \\
0.068 & 411 & 40 \\
\hline
\end{tabular}

The total standing crop of bryophytes for the individual blocks and stones was $165 \mathrm{gm} \mathrm{m}^{-2}$ of attachment area, with a $95 \%$ confidence interval of $\pm 90 \mathrm{gm} \mathrm{m}^{-2}$ assuming normal distribution. The results of the larger transect samples, was $325 \mathrm{gm} \mathrm{m}^{-2}$. This figure however included a very dense local area of $F$. polyphyllus. Both estimates cover the full range of water depths.

The standing crop of $F$. squamosa was $112 \mathrm{gm} \mathrm{m}^{-2}$ of attachment area and $174 \mathrm{gm} \mathrm{m}^{-2}$ by transects. The transects probably gave a better estimate of standing crop even though there was a similarly high variance. The total removal of crop was not possible because the site was used by other workers.

Table 2, - Standing crop by $0.5 \mathrm{~m}$ transects, Artigusse Stream.

\begin{tabular}{|c|c|c|c|c|}
\hline Station & 1 & 2 & 3 & 4 \\
\hline \multicolumn{5}{|l|}{ species $\mathrm{gm} / \mathrm{m}^{2}$} \\
\hline Fontinalis squamosa & 118 & 122 & 216 & 282 \\
\hline Fissidens polyphyllus & 20 & 13 & 233 & 39 \\
\hline Eurhynchium riparioides & 9 & - & 123 & 9 \\
\hline Hepatics & 3 & 2 & - & 3 \\
\hline Filamentous algae & - & - & 10 & - \\
\hline Depth $\mathrm{m}$ & .22 & .56 & .37 & .38 \\
\hline $\begin{array}{l}\text { Total Weight } \\
\text { unattached moss }\end{array}$ & 150 & 137 & 682 & 333 \\
\hline Fontinalis squamosa & - & 47 & - & 342 \\
\hline Eurhynchium riparioides & - & - & - & 5 \\
\hline Total Weight of unattached mosses & - & 47 & - & 347 \\
\hline
\end{tabular}


The system was fairly stable (H. Décamps, pers. comm.); in $F$. squamosa the net production of leaves was presumably accounted for by grazing and accidental loss within the following year and only the stems accumulated. Larger plants had very much more and a relatively greater proportion of stem than smaller ones. The ratio of stem to leaf weight for the current year's growth is about $1: 2$. As leaves are lost within the year, two thirds of the year's production is lost annually. As the system is fairly stable, and assuming the plants are in a linear growth phase, the average plant, four years old, has two thirds of its weight as stems and has produced and lost as much as the existing standing crop. The estimate of minimum net production is $92 \mathrm{gm} \mathrm{m}^{-2}$ per year for $F$. squamosa and is unknown for $F$. polyphyllus even though its standing crop was locally equal to that of $F$. squamosa.

Artigusse water chute.

The mean splash rates were calculated and the results expressed in metres of water per day and plotted on a map of the splash area as isohyets. (Table 3.) Fig. 1.

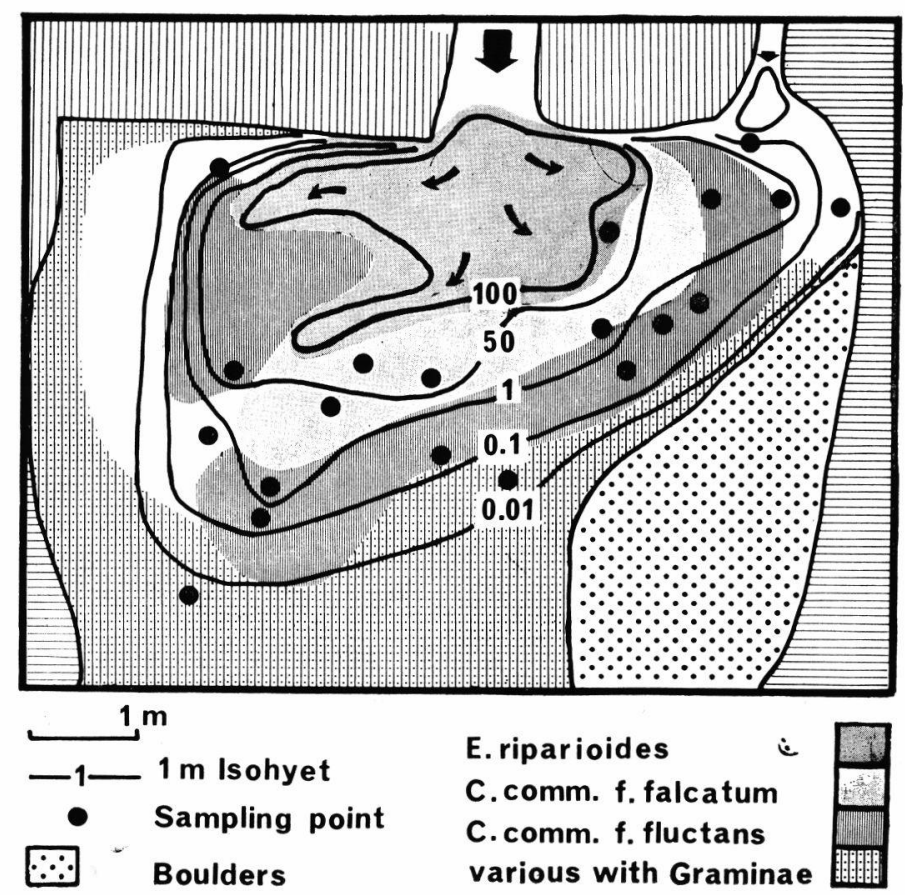

FIg. 1. - Artigusse water chute, topographical with bryophyte species distribution and isohyets of water splash $\mathrm{m}$ day $^{-1}$. 
The main zones of the mosses were :-

Zone 1. In excess of $100 \mathrm{~m}$ day $^{-1}$, dominated by Eurhynchium riparioides except in the direct force of falling water.

Zone 2. 1 - $100 \mathrm{~m} \mathrm{day}^{-1}$, dominated by $C$. commutatum forma falcatum, a thick stemmed and erect form.

Zone 3. 0.1 - $1.0 \mathrm{~m} \mathrm{day}{ }^{-1}$, south facing, dominated by C. commutatum forma fluctans, a soft non erect mat with lips slightly raised.

Zone 4. $0.1 \mathrm{~m} \mathrm{day}^{-1}$, a sheltered trench, north facing, a mixed collection of a very delicate erect form of $C$. commutatum fluctans with members of the genera Amblystegia, Plagiochila and Metzgeria, on a rotting log.

The depth of moss was very variable except in Zone 2 where it reached an average of $30 \mathrm{~cm}$ and the moss formed a saucer shaped bank of material. The cores removed from this zone, contained orange brown debris from $3 \mathrm{~cm}$ below the surface, which was clearly recognisable as $C$. commutatum. The $\mathrm{pH}$ of this "peat" was $4-5$, no animals were found the cores.

TABLE 3. - Mean splash rate $m$ water per day, Artigusse Water Chute.

\begin{tabular}{lc}
\hline Station & Splash $\mathrm{m} \mathrm{day}^{-1}$ \\
\hline $\mathbf{2}$ & 0.01 \\
3 & 59 \\
4 & 0.7 \\
5 & 0.4 \\
6 & 1.1 \\
7 & 1.3 \\
8 & 0.7 \\
9 & 64 \\
10 & 0.1 \\
11 & 0.002 \\
12 & 0.2 \\
13 & 0.02 \\
14 & $100+$ \\
15 & 0.1 \\
16 & 28 \\
17 & 1.8 \\
18 & 0.1 \\
19 & 0.6 \\
20 & 1.9 \\
\hline
\end{tabular}




\section{Estaragne Tributary.}

The area mapped was a length of 25 metres of stream of area $146 \mathrm{~m}^{-2}, 41 \mathrm{~m}^{-2}$ of which twere not considered in standing crop estimates as they were dry for nine months of the year; no bryophytes were present on the small loose stones of the bed. The remaining $105 \mathrm{~m}^{-2}$ had only $15 \mathrm{~m}^{-2}$ of bryophyte cover. Analysis of the results of standing crop samples collected indicated statistically different values were obtained between the three types of surfaces (Table 4). The weighted mean standing crop for the area of bryophyte was $684 \mathrm{gm} \mathrm{m}^{-2}$ (whole stream $98 \mathrm{gm} \mathrm{m}^{-2}$ ). The dominant was $C$. commutatum.

No estimate of production was obtained.

TABLE 4. - Standing crop estimates, Estaragne Tributary.

Square quadrats

$\begin{array}{crc}15 \mathrm{~cm} & \mathrm{gm} \mathrm{dry} w \mathrm{t} \mathrm{m}^{-2} & \text { Type of surface } \\ 1 & 540 & \mathbf{1} \\ \mathbf{2} & 1950 & \mathbf{2} \\ \mathbf{3} & \mathbf{1} 70 & \mathbf{2} \\ \mathbf{4} & 402 & \mathbf{1} \\ \mathbf{5} & 9 & \mathbf{3} \\ \mathbf{6} & \mathbf{9 2} & \mathbf{3} \\ \mathbf{7} & \mathbf{3 6} & \mathbf{3} \\ \mathbf{8} & 14 & \mathbf{3}\end{array}$

Round cores $3.4 \mathrm{~cm}$

$\begin{array}{rr}1 & 181 \\ 2 & 154 \\ 3 & 1320 \\ 4 & 88 \\ 5 & 214 \\ 6 & 198\end{array}$

$\mathbf{1}$
$\mathbf{1}$
$\mathbf{2}$
$\mathbf{3}$
$\mathbf{1}$
$\mathbf{1}$

Total standing crop

\begin{tabular}{|c|c|c|c|c|c|}
\hline Group & Area & Mean & $95 \%$ & confidence limit & Total cron \\
\hline 1 & 4.2 & 281 & & $119-443$ & 1180 \\
\hline 2 & 6.1 & 1456 & & $500-2140$ & 8980 \\
\hline 3 & 4.7 & 40 & & $1-79$ & 188 \\
\hline Total & 15.0 & & & & 10248 \\
\hline \multicolumn{6}{|c|}{ Mean $684 \mathrm{gm} \mathrm{m}^{72}$} \\
\hline
\end{tabular}




\section{CONCLUSION}

There are many difficulties in producing good production and standing crop figures for the two streams due to the high variability of such sites. If sufficient samples were taken in most types of system then the systems would be destroyed. Therefore a combination of monitoring environmental factors, measuring the maximum standing crop achieved in the season, marking individual plants and combined with laboratory experiments under controlled conditions of light, temperature and flow, would produce production estimates with the least harm to the system.

Acknowledgements. - I am indebted to the Professor and staff of the Departement of Hydrobiology, University of Toulouse, for the facilities and help so graciously provided. Special thanks are due to $H$. Décamps who suggested the study areas and took an active interest in the investigations and to D. F. Westlake and Dr M. Ladle for criticising the manuscript.

\section{REFERENCES}

Arnold (Faith) \& Macin (T. T.). 1969. - Studies on the Fauna of a Shropshire Hill Stream. Field Studies, 3 (1).

Ciymo (R. S.). 1970. - The growth of Sphagnum : Methods of Measurement. J. Ecol., 58 (1) : 13-49.

Decamps (H.). 1967. - Ecologie des Trichoptères de la vallée d'Aure (Hautes-Pyrénées). Annls Limnol., 3 : 399-577.

Decamps (H.) et Lafont (M.). 1974. --- Cycles vitaux et production des Micrasema pyrénéennes dans les mousses d'eau courantes (Trichoptera, Brachycentridae). Annls Limnol. (sous presse).

Frost (Winifred E.). 1942. - River Liffey survey. VI. The Fauna of the submerged "mosses" in a acid and an alkaline water. Proc. $R$. Ir. Acad., 47 B : 293-369.

Grame (Janice M.). 1968. - Ecological Observations on some Bryophytes in Appalachian Mountain Streams. Castanea, $33: 300-325$.

Gessner (F.). 1959. - Hydrobotanik 11 Stoffhaushalt, Veb. Deutsch. Ver. Wissensch, Berlin.

Hynes (H. B. N.). 1970. - Ecology of Running Waters. Liverpool University Press.

Minshale (G. W.) \& Kulehne (R. A.). 1969. - An Ecological Study of Invertebrates of the Duddon, an English Mountain Stream. Arch. Hydrobiol., 66 (2) : 169-191.

Nicolau-Guillaumet (P.). 1959. - Recherches faunistiques et écologiques sur la rivière «La Massane». Vie et Milieu, 10: 217-266.

Nyнolm (EIsa). 1954. - Moss Flora of Fennoscandia II Musci. Ed. The Botanical Society of Lund. Gleerup Lund, Sweden.

Vollenweider (R. A.). 1969. - A manual on methods of Measuring Primary Production in Aquatic environments. IBP Handbook No. 12. Blackwell's Scientific Publications, Oxford.

Watson (E. V.). 1968, 2nd Ed. - British Mosses and Liverworts. The University Press Cambridge. 